\title{
Photoreflectance analysis of a GalnP/GalnAs/Ge multijunction solar cell
}

\author{
E. Cánovas, ${ }^{1}$ D. Fuertes Marrón, ${ }^{1, a)}$ A. Martí, ${ }^{1}$ A. Luque, ${ }^{1}$ A. W. Bett, ${ }^{2}$ F. Dimroth, ${ }^{2}$ and \\ S. P. Philipps ${ }^{2}$ \\ ${ }^{1}$ Instituto de Energía Solar. Universidad Politécnica de Madrid, E.T.S.I. Telecomunicación, \\ Ciudad Universitaria s/n. Madrid 28040. Spain \\ ${ }^{2}$ Fraunhofer Institut fitr Solare Energiesystente, Heidenhofstr. 2, 79110 Freiburg, Germany
}

\begin{abstract}
We have analyzed the photoreflectance spectra of a GaInP/GaInAs/Ge triple junction solar cell. The spectra reveal signatures from the window layer and middle and top subcells included in the stack. Additional contributions from the multilayer bufter introduced between the mismatched bottom and middle cells have been detected. Franz-Keldysh oscillations (FKOs) dominate the spectra above the fundamental bandgaps of the GaInP and GaInAs absorbers. From the FKO analysis, we have estimated the dominant electric fields within each subcell. In light of these results, photoreflectance is proposed as a useful diagnostic tool for quality assessment of multijunction structures prior to completion of the device or at earlier stages during its processing.
\end{abstract}

Multijunction solar cells currently represent the most efficient approach to photovoltaic energy conversion, with efficiencies over $40 \%{ }^{1,2}$ The multijunction design pursues the selective absorption of different parts of the solar spectrum by different absorbers in a layer stack so as to optimize the photogeneration and collection of minority carriers and to reduce energy losses related to thermalization of hot carriers. The characterization of multijunction solar cells is complex and the interpretation of results is usually not straightforward. There are techniques available, e.g., quantum efficiency and spectral response, ${ }^{3}$ current-voltage characteristics under illumination and calibration routines thereof, ${ }^{4}$ and electroluminescence. ${ }^{5}$ However, all these techniques require complete cell structures, including metallization and encapsulation of individual devices. It would be of a great interest to expand the diagnostic tools that reveal the optoelectronic quality of the subcells to earlier stages of device completion or even during processing of the multilayer stack. In this letter, the results of photoreflectance (PR) characterization of a triple junction structure without metallization are presented, and the suitability of PR to this aim is demonstrated. The solar cell structure was grown as an epitaxial, latticemismatched (metamorphic) structure by metalorganic vaporphase epitaxy (MOVPE). More details on the MOVPE growth process can be found elsewhere. ${ }^{1}$

Figure 1(a) presents the structure of the $\mathrm{GaInP} /$ GaInAs/Ge triple junction solar cell analyzed in this work. The device includes more than 30 layer steps in a single growth process, including a step-graded buffer consisting of nine layers of $\mathrm{Ga}_{\mathrm{x}} \mathrm{In}_{1-\mathrm{x}} \mathrm{As}$ with increasing In content. This buffer layer has been specifically developed to overcome the lattice mismatch (about $1.2 \%$ ) between the bottom (Ge) and the middle (GaInAs) subcells [Fig. 1(b)]. It also prevents the propagation of misfit dislocations toward the middle subcell, ${ }^{6.7}$ which are potential killers for the device photocurrent output.

$\mathrm{PR}^{8}$ as a contactless form of electromodulation, belongs to the family of modulated spectroscopies. ${ }^{9}$ In our PR setup, (a)

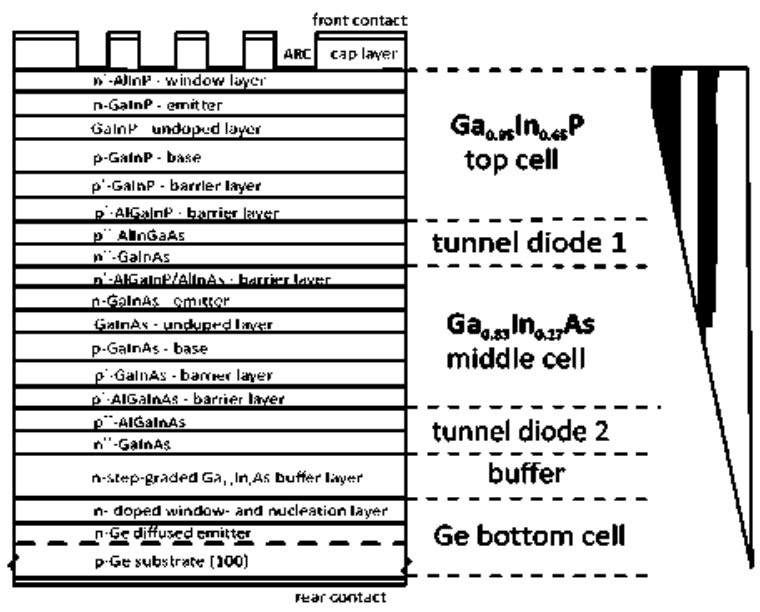

(b)

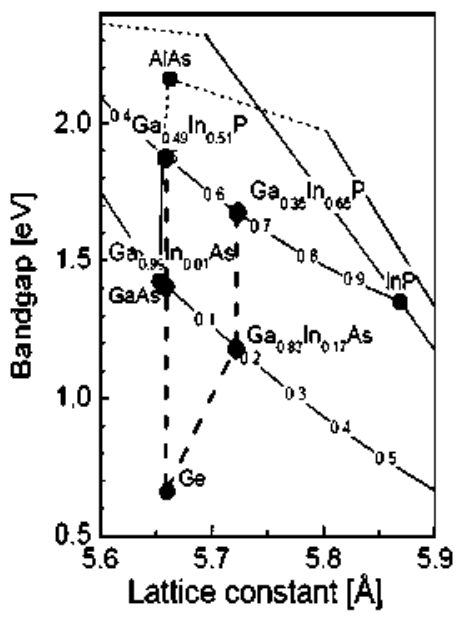

FIG. 1. (Color online) (a) Layer structure of a triple junction solar cell consisting of $\mathrm{Ga}_{0.35} \mathrm{In}_{0.65} \mathrm{P}$ / $\mathrm{Ga}_{0.83} \mathrm{In}_{0.17} \mathrm{As} / \mathrm{Ge}$ absorbets. (b) Diagram of bandgap vs lattice constant of materials used in multijunction solar cells. Dashed lines represent the lattice-matched (vertical) and metamorphic (oblicue) approaches to the growth of III-V compounds onto Ge substrates.

\footnotetext{
"Electronic mail: dfuettes@ies-def.upm.es.
} 


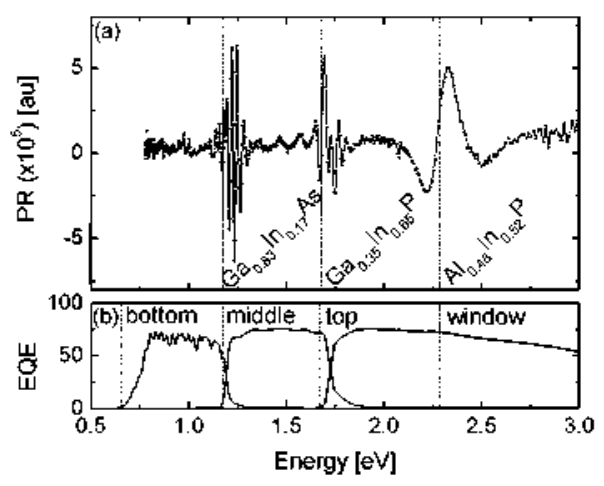

FIG. 2. (Color online) (a) PR spectrum of a $\mathrm{Ga}_{0.35} \mathrm{It}_{0.64} \mathrm{P} / \mathrm{Ga}_{0.83} \mathrm{In}_{0.17} \mathrm{As} / \mathrm{Ge}$ triple junction solar cell obtained with $10 \mathrm{~mW}$ laser pumping at $325 \mathrm{~nm}$ chopped at $777 \mathrm{~Hz}$. Dotted lines denote the fundamental gaps of $\mathrm{Ga}_{0.83} \mathrm{In}_{0.17} \mathrm{As}(1.18 \mathrm{eV}), \mathrm{Ga}_{0.35} \mathrm{In}_{0.65} \mathrm{P}(1.67 \mathrm{eV})$, and $\mathrm{Al}_{0.48} \mathrm{In}_{0.52} \mathrm{P}(2.28 \mathrm{eV})$. (b) QE measurement of a fully functionally solar cell fabricated from the analyzed wafer.

the light (probe beam) from a $250 \mathrm{~W}$ quartz lamp is spectrally decomposed by a $1 / 8 \mathrm{~m}$ monochromator. The resulting monochromatic beam is reflected by the sample and detected by Ge or Si detectors. A HeCd $(325 \mathrm{~nm}, 15 \mathrm{~mW})$ laser beam (pump beam), mechanically chopped at $777 \mathrm{~Hz}$, impinges on the sample within the spot of the probe beam. Low-pass optical filters prevent scattered laser light entering the detectors. Changes in reflectivity due to the modulated beam are measured as a function of the wavelength by a lock-in amplifier and recorded by a computer. The measurement procedure results in sharp, derivativelike spectral features at those energies where interband transitions occur.

Figure 2(a) shows a characteristic PR spectrum of the analyzed triple junction structure at room temperature. Dotted lines mark the fundamental gaps of three absorption onsets, with estimated values of $2.28,1.67$, and $1.18 \mathrm{eV}$, corresponding to the fundamental transitions of the AlInP window and the top and middle cells, respectively. From these figures, alloy compositions of $\mathrm{Al}_{0.48} \mathrm{In}_{0.52} \mathrm{P}$ (from the direct transition of the window layer ${ }^{10}$ ), $\mathrm{Ga}_{0.35} \mathrm{In}_{0.65} \mathrm{P}$ (for the top cell), and $\mathrm{Ga}_{0.83} \mathrm{In}_{0.17} \mathrm{As}$ (for the middle cell) have been estimated. It is worth commenting that the fundamental absorption edge of $\mathrm{Ge}$ (bottom cell) at $0.66 \mathrm{eV}$, which is out of our detectivity range, is PR-silent due to its indirect nature. Direct transitions of Ge above its indirect bandgap ${ }^{11}$ (e.g., $\mathrm{E}^{\mathrm{Ge}}{ }_{1}=0.80 \mathrm{eV}$ ) can, in principle, be monitored by PR; however, this is not the case under our experimental conditions, as can be seen in Fig. 2(a). For comparison purposes, a section of the analyzed wafer has been processed into an operative solar cell, the quantum efficiency $(\mathrm{QE})$ of which is presented in Fig. 2(b). A good correlation between the absorption thresholds is observed between PR and QE data. This corroborates the ability of PR, a contactless and nondestructive technique, to determine alloy compositions for each subcell prior to metallization or even in situ during the growth. $^{12}$

Before going into a more detailed analysis of the richly featured PR spectra, an issue observed in Fig. 2(a) deserves special attention: the entire device structure (excluding the bottom cell) is effectively modulated by the UV laser beam. This point is demonstrated by the detection of PR signatures stemming from the $\mathrm{Ga}_{0.83} \mathrm{In}_{0.17} \mathrm{As}$ middle absorber in the multijunction cell even when the laser beam is expected to be completely absorbed at the AlInP window and
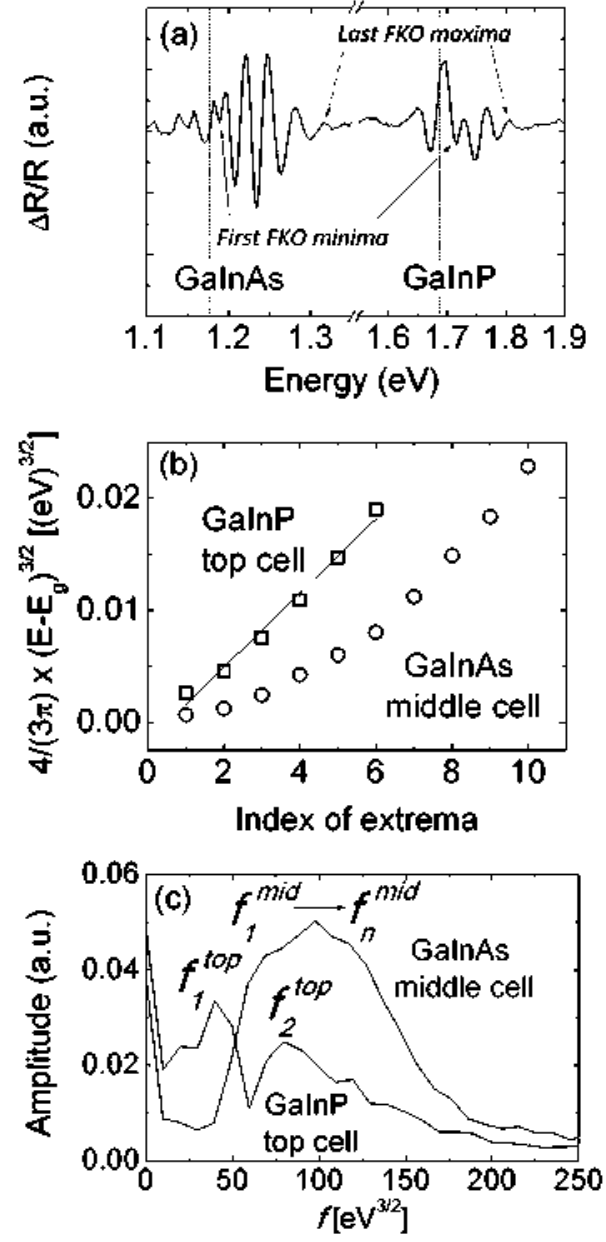

FIG. 3. (Color online) (a) Expanded view of the PR spectium of Fig. 2(a) and assignment of oscillation indices for the analysis of FKOs. (b) Standard and (c) Fouriet analyses of the oscillatory regimes of PR from the middle and top cells.

$\mathrm{Ga}_{0.35} \mathrm{In}_{6.65} \mathrm{P}$ top cell. This aspect, as discussed previously from PR measurements on GaAs wafers, ${ }^{13}$ is a direct proof of minority carrier diffusion, rather than the penetration depth of the pump beam, as the dominant factor determining the probed region in PR. It represents an intrinsic advantage of this characterization method, as compared to, e.g., photoluminescence, ${ }^{14}$ where the laser penetration depth limits the probing of buried layers.

An expanded view of the PR spectrum shown in Fig. 2(a) is presented in Fig. 3(a). The plot shows features related to the top and middle cells. Again, dotted lines in Fig. 3(a) indicate the estimated fundamental gaps of the different subcells. Below the bandgap of the $\mathrm{Ga}_{0.83} \mathrm{In}_{4.17} \mathrm{As}(1.18 \mathrm{eV})$ middle cell, a number of minor features are observed, which cannot be ascribed to any of the direct transitions of $\mathrm{Ge}$ at the bottom cell. Their origin is presumably related to the $\mathrm{Ga}_{\mathrm{x}} \mathrm{In}_{1-\mathrm{x}}$ As buffer layer [see Fig. 1(a)] and most likely to the presence therein of an overshooting layer ${ }^{7}$ with a higher In content than the $\mathrm{Ga}_{0.83} \mathrm{In}_{0.17} \mathrm{As}$ middle cell. These features could also be contributed by the presence of crystalline defects accumulated at the buffer layer. ${ }^{6,7}$ It is worth mentioning that PR apparently provides a way of probing the quality of the buffer layers in complete devices.

The PR signals of the middle and top cells presented in Fig. 3(a) are dominated by Franz-Keldysh oscillations (FKOs) above their fundamental gaps, ${ }^{15}$ which are a direct 
measure of built-in electric fields present in the sample (e.g., at space charge regions). FKOs in the PR spectra at energies above a critical point can be described by ${ }^{16}$

$$
\frac{\Delta R}{R} \propto \cos \left\{\frac{4}{3} \frac{\left[E-E_{g}\right]^{3 / 2}}{h \theta}+\frac{\pi(d-1)}{2}\right\},
$$

where $(h \theta)^{3}=\mathrm{e}^{2} h^{2} F^{2} /\left(2 \mu_{i}\right)$ is the electro-optical energy, $d$ is the dimensionality of the critical point, $F$ is the intensity of the electric field, and $\mu_{i}$ is the reduced interband effective mass in the direction of the field. The extrema of the oscillations satisfy

$$
n \pi=\varphi+\frac{4}{3} \frac{\left[E_{n}-E_{g}\right]^{3 / 2}}{\hbar \theta},
$$

where $n$ is the index of the extrema (an integer), $\varphi$ is a phase factor, and $E_{n}$ is the energy of the $n$th extremum. The magnitude of the electric field can be directly extracted from the slope of a plot of $(4 / 3 \pi)\left(E_{n}-E_{g}\right)^{3 / 2}$ as a function of the index $n$, as seen in Fig. 3(b) (note that, conversely, $\mu$ can be estimated if the electric field is know11). For the $\mathrm{Ga}_{0.35} \mathbf{I n}_{0.65} \mathrm{P}$ top cell [considering $\mu=0.66 m_{0}$ (Ref. 17)], the field magnitude obtained is $137 \mathrm{kV} / \mathrm{cm}$, which represents the maximum field within the top subcell structure and is in good agreement with theoretical calculations carried out in the semiconductor simulation environment Sentaurus TCAD from Synopsys. The simulations show that the electric field is particularly strong at the interface between the base layer and the backsurface field. This results from the strong difference in doping and bandgap between these two layers. For the $\mathrm{Ga}_{0.83} \mathrm{In}_{0.17} \mathrm{As}$ middle cell, the plot does not show a linear dependence on the index of the extrema [see Fig. 3(b)], indicating that the FKO signal is contributed to by more than one electric field. A simple analysis of the FKOs' extrema is inappropriate in this case. However, if all information regarding the magnitude of the electric field is contained within the period of the oscillation fringes, ${ }^{18}$ we can ascertain the different contributions to the oscillatory regime of the PR spectrum using the fast Fourier transform (FFT) method [Fig. 3(c)]. For the top cell [black trace in Fig. 3(c)], we obtain two contributions to the electric field $f_{1}$ top and $f_{2}{ }^{\text {top }}$ ) that we attribute to the light $\left(f_{1}{ }^{\text {top }}\right)$ and heavy $\left(f_{2}{ }^{\text {top }}\right)$ hole transitions from the same GaInP layer since the frequencies of the peaks yield the same electric field within the experimental error $\left[F_{l h}=103 \pm 10 \mathrm{kV} / \mathrm{cm}\right.$ and $F_{h h}$ $=110 \pm 11 \mathrm{kV} / \mathrm{cm}$, after $\mu_{h h}=0.66 m_{0}$ and $\mu_{h h}=0.145 m_{0}$ (Ref, 17)]. From the FFT analysis of the $\mathrm{Ga}_{0.83} \mathrm{In}_{0.17} \mathrm{As}$ middle cell, we conclude that the FKOs present in the PR spectra [Fig. 3(a)] are contributed to by several electric fields $\left[f_{1}^{\text {mid }} \rightarrow f_{n}^{\text {mid }}\right.$, Fig. 3(c)], in agreement with the nonlinearity of the standard FKO analysis [Fig. 3(b)]. In this case, the origin of the fields is unclear, as they can originate at various interfaces in the buffer and middle subcell. We interpret the broad FFT spectrum for the middle cell as the result of a combination of field contributions from the doped graded buffer layers. No further attempt at isolating individual contributions of each layer of the buffer will be made in this contribution. It is, nevertheless, worthwhile to stress again the fact that the method is, in principle, sensitive to this issue. The quantification of the magnitude of the electric fields at the interfaces of the $\mathrm{Ga}_{0.83} \mathrm{In}_{0.17} \mathrm{As}$ and $\mathrm{Ga}_{0.35} \mathrm{In}_{0.65} \mathrm{P}$ subcells is accessible provided the different signatures embedded in the oscillatory part of the spectrum are confidently identified. The particular assessment of the different transitions observed over the whole device structure may be done by comparing the present results with, e.g., test samples consisting of single absorbers. However, this aspect is outside the scope of the present letter.

In summary, we have presented a PR analysis of a triple junction solar cell structure. The PR spectra obtained at room temperature contain abundant information about the multilayer stack not easily accessible by other techniques, such as those based on luminescence or quantum efficiency. Our results clearly demonstrate the suitability of $P R$ as a characterization and diagnostic tool for this type of device structure. Due to the inherent complexity of such structures, further advances are expected from experiments designed on a differential basis.

This work has been supported by the European Commission (IBPOWER project, Contract No. 211640), the Spanish Ministry of Science and Innovation (NANOGEFFES project, Contract No. ENE2009-14481-C02-01), and Comunidad de Madrid (NUMANCIA-2 project, Contract No, $\$ 2009 /$ ENE1477). S. P. Philipps gratefully acknowledges the scholarship support of the German Federal Environmental Foundation.

'W. Guter. J. Schöne, S. P. Philipps, M. Steiner. G. Siefer. A. Wekkeli. E. Welser. E. Oliva, A. W. Bett. and F. Dimroth. Appl. Phys. Lett. 94. 223504 (2009).

${ }^{2}$ R. R. King, D. C. Law, K. M. Edmondson. C. M. Fetzer. G. S. Kinsey. H. Yoon, R. A. Sherif, and N. H. Karam, Appl. Phys. Lett. 90, 183516 (2007).

${ }^{3}$ M. Meusel, C. Baur, G. Letay, A. W. Bett, W. Warta, and E. Fernandez, Prog. Photovoltaics 11, 499 (2003).

${ }^{4}$ K. Emery, M. Meusel, R. Beckett, F. Dimroth, A. Bett, and W. Warta, Proceedings of the 28th IEEE Photovoltaic Specialists Conference. Anchorage. Alaska, 2000 , p. 1126.

${ }^{5}$ T. Kirchartz, U. Rau, M. Hermle, A. W. Bett, A. Helbig, and J. H. Werner, Appl. Phys. Lett. 92、123502 (2008).

${ }^{6}$ A. W. Bett. C. Baur, F. Dimroth, and J. Schöne, in Materials Research Society Symposia Proceedings (Mater. Res. Soc. Synup. Proc., Warrendale. PA, 2005) Vol. 836, L6.4.1.

${ }^{7}$ F. Dimroth, W. Guter, J. Schöne, E. Welser, M. Steiner, E. Oliva, A. Wekkeli. G. Sjefer, S. P. Philipps, and A. W. Bett. Proceedings of the 34th IEEE PV Specialists Conference, Philade]phia, 2009, p. 1038.

${ }^{8}$ J. Misiewicz, P. Sitarek, G. Sek, and R. Kudrawiec, Mater. Sci. Poland 21, $263(2003)$.

${ }^{9} \mathrm{M}$. Cardona. Modulation Spectroscopy (Academic, New York. 1969).

${ }^{10} \mathrm{Y}$. Gu, Y. G. Zhang. H. Li, A. Z. Li, and Z. Zhu, Mater. Sci. Eng., B 131. 49 (2006).

${ }^{11}$ F. H. Pollak and M. Cardona, Phys. Rev. 172, 816 (1968).

${ }^{12}$ F. H. Pollak, Surf. Interface Anal. 31. 938 (2001); F. H. Pollak and H. Shen, J. Cryst. Growth 98, 53 (1989).

${ }^{13}$ Y. Mochizuki. T. Ishii, and M. Mizuta, Jpn. J. Appl. Phys., Part 1 34, 6106 (1995).

${ }^{14}$ R. R. King, M. Haddad, T. Isshiki, P. C. Colter, J. H. Ermer, H. Yoon, D. E. Joslin, and N. H. Karam. Proceedings of the 28th IEEE Photovoltaic Specialists Conference, Anchorage, Alaska, 2000, p. 982.

${ }^{15}$ H. Shen and M. Dutta, J. Appl. Phys. 78, 2151 (1995).

${ }^{16}$ D. E. Aspnes and A. A. Studna, Phys. Rev. B 7, 4605 (1973).

${ }^{17}$ F. Onnes and M. Razeghi. Appl. Phys. Lett. 59. 1034 (1991).

${ }^{18}$ D. P. Wang and C. T. Chen, Appl. Phys. Lett. 67, 2069 (1995) 